\title{
MELANOSIS VESICAL: UNA ENTIDAD DE MUY INFRECUENTE PRESENTACIÓN
}

\author{
J.L. PALMERO MARTÍ, S. ARLANDIS GUZMÁN, E. BROSETA RICO, \\ M. GUILLEN NAVARRO, J.V. SALOM FUSTER*, J.F. JIMÉNEZ CRUZ
}

Servicios de Urología y *Anatomía Patológica. Hospital Universitario La Fe. Valencia.

Actas Urol Esp. 28 (8): 614-616, 2004

\section{RESUMEN}

MELANOSIS VESICAL: UNA ENTIDAD DE MUY INFRECUENTE PRESENTACIÓN

La melanosis vesical es una entidad caracterizada por depósito anómalo de pigmento melánico en la mucosa urotelial sin atipia celular asociada, que condiciona una coloración oscura de la mucosa vesical en su visión macroscópica. Es muy infrecuente, ya que, en nuestra revisión de la literatura únicamente encontramos cinco casos publicados. El potencial biológico de esta entidad es desconocido, debido a la extremada rareza en su presentación. Presentamos un caso de melanosis vesical confirmado por estudio histológico y análisis inmunohistoquímico. Pensamos que es necesario tener presente la existencia de esta entidad, así como saber reconocerla para poder establecer el diagnóstico diferencial con el melanoma vesical maligno.

PALABRAS CLAVE: Melanosis vesical. Pigmento melánico. Inmunohistoquimia.

\section{ABSTRACT}

MELANOSIS OF THE BLADDER: A VERY UNCOMMON ENTITY

Melanosis of the bladder is a rare entity characterized by anomalous deposits of melanin-containing pigment on the vesical urothelium without melanocytic atypia or associated malignant melanoma. To our knowledge and following such strict criteria, there are only five cases previously reported. The biological potential of this entity is uncertain because of the rarity of their. We report one case of simple melanosis of the bladder confirmed by histological examination and inmunohistochemistry analysis. We believe that recognition of this entity is important.

KEY WORDS: Bladder melanosis. Melanin-containing pigment. Inmunohistochemistry.

$\mathrm{L}$ a pigmentación oscura que adquiere la mucosa vesical por acumulo de pigmento melánico, definida como melanosis, en los casos en los que no existe atipia celular asociada, es un hecho extremadamente infrecuente, como hemos podido observar en base a los resultados de la revisión literaria que hemos realizado. En la literatura mundial, tan sólo encontramos cinco casos de melanosis vesical, lo que habla de la rareza de este proceso. Alroy et al. son los primeros en comunicar la presencia de esta entidad en base a dos casos que datan del año $1986^{1}$.
A pesar de esta rareza, es necesario conocer esta entidad, ya que exige hacer un diagnóstico diferencial con el melanoma vesical maligno, sobre todo en casos de lesiones localizadas. Esta última entidad comporta un mal pronóstico para el paciente, de ahí la necesidad de este diagnóstico diferencial.

\section{CASO CLÍNICO}

Presentamos el caso de un paciente varón de 75 años con antecedentes de cardiopatía isquémica y de enfermedad de Parkinson que acude al 
servicio de urgencias de nuestro centro por dolor lumbar de carácter continuo y síndrome miccional tipo mixto (obstructivo e irritativo) de larga evolución .La exploración física fue normal con un tacto rectal no sugerente de malignidad, siendo la próstata elástica y plana grado II/IV. En el estudio ecográfico se apreció la presencia de una hidronefrosis bilateral junto a una imagen de vejiga muy trabeculada que apenas se vaciaba con la micción espontánea. Inicialmente se colocó sonda vesical y se inició tratamiento alfabloqueante, consiguiendo la retirada de la sonda y control satisfactorio de la clínica miccional. El paciente fue seguido de manera periódica en nuestra consulta externa, donde se completó el estudio con PSA que presentó cifras dentro de la normalidad. En uno de los controles ecográficos realizados se detectó la presencia de una imagen exofítica en pared lateral de la vejiga. Por este motivo se solicitó una uretrocistoscopia (Fig. 1) que mostró una mucosa vesical extremadamente trabeculada con áreas extensas de mucosa vesical ennegrecidas que ofrecía un aspecto característico al alternar con otras de mucosa sana. En la exploración se descartó la presencia de tumor vesical alguno, resultando ser la imagen ecográfica producto de alguno de los pliegues de la

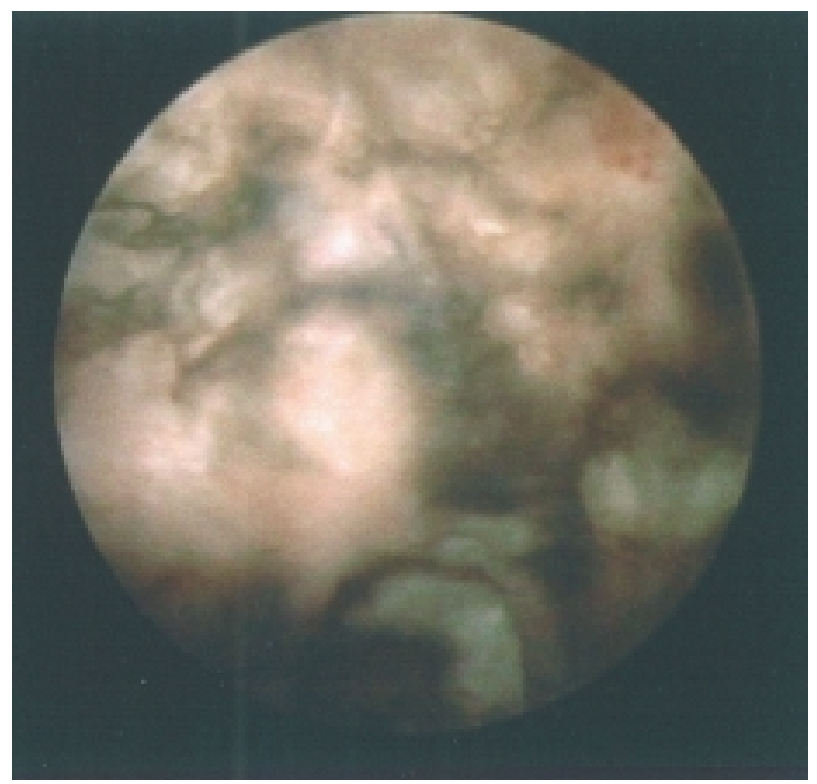

FIGURA 1: Imagen de uretrocistoscopia en la que podemos apreciar áreas de mucosa vesical de color oscuro (ennegrecidas) alternando con otras de mucosa congestiva de aspecto macroscópico normal. mucosa. En esta exploración, se tomaron biopsias con pinza fría de las zonas ennegrecidas, que revelaron la presencia de depósitos de pigmento oscuro en el urotelio y lámina propia (mayor concentración a este nivel) sin apreciar atipias celulares en el examen histológico del tejido analizado. Mediante técnicas de inmunohistoquimia se confirmó la naturaleza melánica del pigmento; HMB-45 (Monoclonal Antibody; Enzo Biochem, New York NY), MART-1, S-100 protein (Dakopats A/S) y Masson-Fontana que resultaron positivas, emitiéndose por tanto el diagnóstico de melanosis vesical (Fig. 2). En la actualidad, y con un seguimiento superior a dos años, el paciente sigue controles periódicos por su clínica de prostatismo sin presentar ninguna otra sintomatología ni dato que evidencien cambios significativos a nivel de la mucosa vesical.

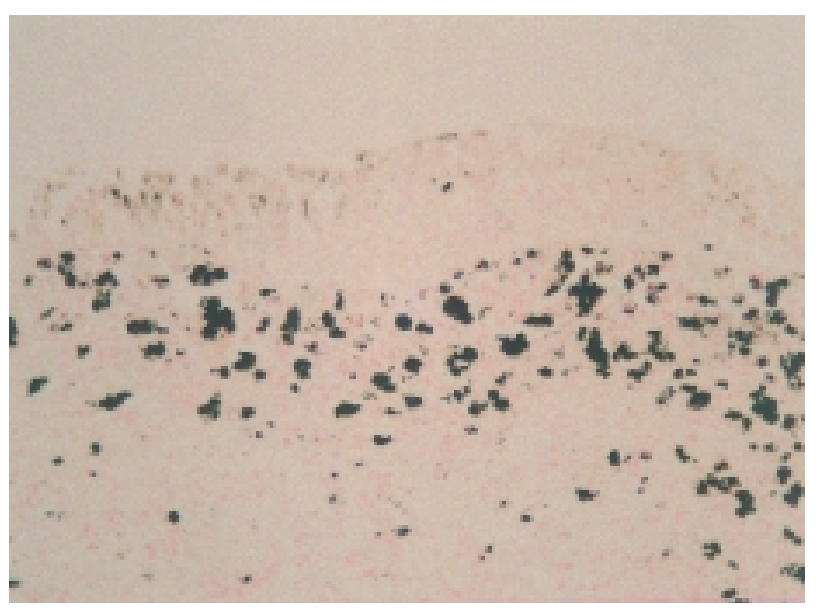

FIGURA 2: Visión microscópica (400x) de la mucosa vesical obtenida mediante biopsia. Se pueden observar numerosos depósitos de pigmento melánico en la lámina propia.

\section{DISCUSIÓN}

El depósito de pigmento melánico a nivel del tracto urinario es un hecho infrecuente, habiéndose comunicado casos a diversos niveles (próstata, uretra, vejiga), siendo los casos de melanosis vesical (5 casos publicados en la literatura revisada), inferiores a los de melanoma maligno coincidente o no con focos de melanosis ${ }^{1-3}$. Sin embargo, estos depósitos en ausencia de atipia celular (melanosis) se consideran más habituales en otras localizaciones como la mucosa del colon y la oral ${ }^{2,3}$. 
La mucosa vesical no contiene melanocitos en su constitución histológica habitual, y por tanto, la histogénesis de este tipo de lesiones a éste y a otros niveles del tracto genitourinario es un hecho objeto de discusión. En este sentido existen diversas opiniones que abogan por un origen "primario" de los melanocitos a partir de células pluripotenciales (stem-cells) del urotelio, o bien, que el origen de los mismos sea consecuencia de una alteración en la embriogénesis ${ }^{2}$, que provocaría que remanentes celulares procedentes de la cresta neural se alojaran en el urotelio debido a una alteración en el proceso migratorio.

El diagnóstico de esta entidad lo establecerá la anatomía patológica del material biopsia, que habitualmente es sometido a estudio con microscopía y distintas técnicas histoquímicas, caracterizándose por la positividad en las técnicas que denotan presencia de pigmento melánico, tales como; Masson-Fontana, HMB-45, MART-1, S100. De estas, HMB-45 se considera la más específica para la detección de células melánicas ${ }^{4-5}$.

Resulta necesario establecer diagnóstico diferencial de esta entidad con el melanoma vesical maligno, entidad que se presenta con similar infrecuencia. En la revisión realizada por De Torres et al., tan sólo se recogen once casos de melanoma vesical maligno en la literatura mundial $^{5}$. El diagnóstico de esta entidad se basa en una serie de criterios que Ainsworth establece en 1976 con modificaciones posteriores que Stein y Kendall en 1984. En base a estos criterios, para el diagnóstico de melanoma vesical primario es necesario, entre otros, la presencia de melanocitos atípicos en el estudio microscópico de la lesión ${ }^{4,5}$. Este aspecto permite diferenciar en el diagnóstico al melanoma maligno de la melanosis vesical, aunque se han descrito casos de melanoma vesical maligno con focos asociados de mela$\operatorname{nosis}^{2,4}$.

El potencial biológico de la melanosis no es del todo conocido, sin embargo la melanosis de la mucosa oral, la más común y mejor estudiada, no ha evidenciado hasta el momento capacidad de malignización ${ }^{2}$. En la melanosis vesical, no se ha establecido hasta el momento tal posibilidad en los 5 casos publicados en la literatura. A pesar de lo expuesto consideramos necesario el control de estos pacientes, al menos con uretrocistoscopia anual. En nuestro caso, el paciente sigue controles, con un seguimiento actual superior a dos años, sin evidenciar hasta el momento cambios significativos en los controles que se le han realizado.

\section{CONCLUSIONES}

A pesar de la extremada rareza de la melanosis vesical, consideramos que es una entidad que debe ser conocida por el especialista en urología, ya que, se ha descrito en la literatura mundial y debe ser diferenciada de otros procesos malignos como el melanoma vesical. De otra parte, dada la ausencia de casos descritos de malignización en la melanosis de la mucosa oral (más frecuente y mejor estudiada), creemos que puede ser considerada una entidad benigna, sin embargo su escasa frecuencia de presentación (tan solo 5 casos previamente publicados), hace que su potencial biológico no sea conocido, por ello recomendamos controles periódicos con uretrocistoscopia.

\section{REFERENCIAS}

1. Alroy J, Ucci AA, Heaney JA. Multifocal pigmentation of prostatic and bladder urothelium. J Urol. 1986;136:96-97.

2. Rossen K, Petersen MM. Simple melanosis of the bladder. J. Urol. 1999;161:1564.

3. Chong FK, Wolfe GZ, Coukos WJ. Melanosis vesica urinaria: Is it a malignant lesion? J. Urol. 1999;161:1904-1905.

4. Kojima T, Tanaka T, Yoshimi N. Primary malignant melanoma of the urinary bladder. Arch Pathol Lab Med. 1992;116: 1213-1216.

5. De Torres I, Fortuño MA, Raventos A. Primary malignant melanoma of the bladder: inmunohistochemical study of a new case and review of the literatura. J. Urol. 1995;154: 525-527.

Dr. J.L. Palmero Martí

Servicio de Urología

Hospital Universitario La Fe

Avda. Campanar, 21

46009 Valencia

(Trabajo recibido el 17 octubre de 2003) 